Article

\title{
Developing a Decision-Making Framework for Regenerative Precinct Development
}

\author{
William Craft $* \mathbb{C}$, Lan Ding $(\mathbb{1})$ and Deo Prasad \\ School of Built Environment, UNSW Sydney, Sydney, NSW 2052, Australia; lan.ding@unsw.edu.au (L.D.); \\ d.prasad@unsw.edu.au (D.P.) \\ * Correspondence: w.craft@unsw.edu.au
}

Citation: Craft, W.; Ding, L.; Prasad, D. Developing a Decision-Making Framework for Regenerative Precinct Development. Sustainability 2021, 13, 12604. https://doi.org/10.3390/ su132212604

Academic Editor:

Jurgita Antuchevičienè

Received: 24 September 2021

Accepted: 12 November 2021

Published: 15 November 2021

Publisher's Note: MDPI stays neutral with regard to jurisdictional claims in published maps and institutional affiliations.

Copyright: () 2021 by the authors. Licensee MDPI, Basel, Switzerland. This article is an open access article distributed under the terms and conditions of the Creative Commons Attribution (CC BY) license (https:// creativecommons.org/licenses/by/ $4.0 /)$.

\begin{abstract}
The consequences of the extractive and disconnected relationship with nature that has dominated past and current sustainability approaches are now being witnessed. A harmonious relationship with nature needs to be reestablished to guide how we can live, act and respond to the global climate emergency. Regenerative development has emerged as a process which enables the reconnection between human and natural systems to create the necessary conditions for a healthy and thriving future. While several frameworks and tools have been developed to support the implementation of regenerative development practices, few deal specifically with decision-making and its associated challenges and opportunities. Responding to this, the purpose of this paper is to present the development of a novel decision-making framework for regenerative precinct development. It is an evidence-based framework established from the key findings of a qualitative case study investigation into the decision-making approaches of regenerative precinct developments. It is a visual guiding framework that poses challenging questions to enable decision-makers to structure and align their thinking, decisions and actions with the fundamental principles of regenerative development. This paper discusses the framework's development, its key features and theoretical basis, and its potential to influence decision-making practices towards regenerative development.
\end{abstract}

Keywords: regenerative development; regenerative design; decision-making; decision-making framework; net-positive

\section{Introduction}

Now, more than ever, we are witnessing the consequences of the extractive and disconnected relationship with nature that has dominated past and current sustainability approaches. These consequences are unequivocally presented in the recent Intergovernmental Panel on Climate Change assessment report (AR6) which reinforces the urgency of collective action to ensure a liveable, resilient and thriving future [1]. Accordingly, there is growing consensus that our current sustainability approach, which is primarily focused on continual improvements to efficiency towards an aspiration of doing no harm, is inadequate in responding to the global climate emergency [2]. What is needed is to reestablish a deeper connection with nature to guide how we should live, act and respond to these global challenges. This requires a fundamental shift away from the prevailing reductionist and mechanistic worldview towards an ecological one, which repositions humanity, its social structures and its biophysical environment as part of a larger community of life [3-7].

The importance of transitioning towards this ecological worldview has been widely discussed across a diverse range of fields, from environmental and global sociology to psychology, spirituality and indigenous knowledge systems [4,6]. Environmental sociologists, for example, have highlighted significant problems associated with the prevailing reductionist approaches that disconnect humanity and nature, calling for more harmonious and co-creative efforts to address global environmental challenges [8-10]. Guiding these efforts is a recognition that human and natural systems are intertwined and interacting 
in the way that societies have not only been passively shaped by their environments but have also played an active and persistent role in shaping these environments [9]. In doing so, humanity and nature are both seen as collective, mutually inclusive actors shaping the whole system, which not only provides opportunities for establishing climate resilient developments and societies $[8,11]$, but to explore how more productive and positive synergies with nature can be achieved and articulated [10].

Regenerative development has emerged as one such process that actively seeks to establish a positive and reciprocal relationship with nature by realigning our values, decisions and actions in a more contributive and harmonious partnership between human and natural systems [12]. What has resulted from this is a compelling alternative to sustainability in the built environment that moves beyond an exercise in increasing efficiency to an approach that actively seeks to make positive contributions to the entire social-ecological system by "cultivating the capacity and capability in people, communities and natural systems to renew, sustain and thrive" [13] (p. 2).

This regenerative approach has been gaining traction recently as the next step for sustainable development, despite its underlying ideas and processes being practiced for over 60 years [14]. A systematic review of key literature in this field by [15] suggests that regenerative development's strong philosophical basis clearly highlights its transformational potential but many challenges remain in its translation and implementation in practice. There is a growing body of research that has therefore sought to identify the key opportunities, drivers and barriers to implementing regenerative development, particularly at a precinct scale [16,17]. This is because the precinct scale, synonymous with a neighbourhood scale, can be seen as the nexus between cities and buildings and offers potential for more meaningful engagement and stewardship within the community [18].

In response to these opportunities and challenges, several frameworks and tools have emerged to support the adoption and implementation of regenerative development practices such as the Regenesis model [7,12], the LENSES Framework [19] and the STARfish Tool [20]. Aligned with the well-defined values and aspirations of regenerative development in existing literature, these frameworks and tools have started to facilitate practical applications of regenerative development. However, few of these regenerative frameworks and tools, as well as investigations into the projects that they have enabled, deal specifically with decision-making and its associated challenges and opportunities throughout the development process.

\section{Aim and Novelty}

In response to this gap, this paper presents the development of a novel decisionmaking framework that supports and guides decision-making throughout the regenerative development process at a precinct scale. It is an evidence-based framework developed from a qualitative investigation into the decision-making approaches of four case study precincts in Australia that are aligned with regenerative development ideas, processes and aspirations. This qualitative investigation is one of the first empirical studies that has sought to understand the decision-making approaches of multiple and diverse regenerative precinct developments. Guiding this study was one overarching question: what decisionmaking approach can facilitate regenerative precinct development and how can it be supported and encouraged? The initial key findings of this study are discussed by an additional paper by the authors [21].

The aim of this paper is to demonstrate how the key findings from this qualitative case study investigation informed and enabled the development of a decision-making framework for regenerative precinct development. This paper discusses how the framework was developed, its key features and elements, its potential significance to influence decision-making practices towards regenerative development, and future directions for its ongoing evolution and improvement. 


\section{Regenerative Development}

Regenerative development has emerged from the need to shift away from the anthropocentric, efficiency and technology-driven approaches of contemporary sustainability that are clearly insufficient in addressing the scale and urgency of the global climate emergency $[14,22]$. At its core, regenerative development is an ongoing process of realigning and reconnecting with the creative efforts and evolution of nature [4,7]. While this biocentric and ecocentric quality has strong theoretical foundations across a diverse range of fields, regenerative approaches have only started to gain traction relatively recently within the built environment. This emergence has led to differences in definitions, terminology and approaches (e.g., regenerative design, regenerative sustainability, net-positive design, regenerative cities, etc.), but all represent a significant departure from the reductionist and mechanistic sustainability discourses [22]. A review of key literature in this field has revealed five interconnected principles that are typically considered fundamental to regenerative development and that distinguish it from this prevailing sustainability paradigm. These interconnected principles are briefly presented below from the perspective of decision-makers to provide context for the development of the decision-making framework:

- Living systems thinking. Decision-makers have an ability to frame their thinking, decisions and actions within a holistic and ecological mindset. This means developing an understanding of a project not from its individual parts but through the interactions and relationships between them that form one complex and dynamic social-ecological system [6]. It also refers to an ability to see themselves and the work they do as no longer separate from or above nature but as an indivisible and co-creative contributor of the biosphere [4];

- Place-specific. Decision-makers work from a profound understanding of a project's unique place. This requires understanding and conceptualizing how a place sustains and self-organizes itself from its entire network of systems within a specified geographical area [6,7]. Achieving this requires processes that go beyond gathering isolated packages of knowledge in disciplinary silos, which are typically focused only on the material reality of a site or human-orientated endeavors [2,23];

- New collective processes. Decision-makers engage and empower a wider range of traditional and non-traditional stakeholders (e.g., ecologists, artists, sociologists, regulatory authorities, etc.) to become co-creators and co-investors, working together to realize the potential of a project and its place [12]. These new collective processes create opportunities to facilitate and expand transdisciplinary thinking, decisions and actions, and to identify place-specific benefits and synergies [12,24];

- Co-evolutionary and transformative. Decision-makers understand that a project's physical completion is not the end of the regenerative development process but actually the beginning, as it marks the start of an ongoing co-evolutionary partnership with nature. Decision-makers therefore consider ways to build the capacity and capability of individuals and communities to continually work towards bringing new value and potential to its place [12];

- Adding positive value. Decision-makers collectively discover how a project can positively contribute towards the health and ongoing viability of "all of the natural, cultural and economic systems that it affects in a place" [7] (p. 28). Decision-makers therefore understand that adding positive value is not a simple accounting exercise of consuming less and generating more, but about redefining value in terms of benefits to all life and enabling new potential for the entire social-ecological system $[6,25]$.

\section{Towards Regenerative Decision-Making}

If regenerative development can be understood as the weaving together of these five fundamental principles, a considerably different understanding of decision-making in the built environment emerges. In the context of sustainability in the built environment, decision-making is typically focused on quantitatively optimizing predetermined 
alternatives to increase efficiency. This is clearly evident in the numerous examples of decision-making frameworks and tools for sustainable development in existing literature that are centered around multi-criteria decision-making techniques such as the analytic hierarchy process [26]. While these decision-making frameworks and tools have provided valuable and necessary contributions, it has been argued that they are inherently reductionist and hierarchical [20].

Aligned with these five fundamental principles, decision-making from a regenerative perspective would instead be seen as a more exploratory, immersive, holistic and collaborative way of making decisions that is oriented towards creating a harmonious and thriving future for all life. The primary motivation and purpose of the decision-making framework developed by this study is to provide the theoretical and practical guidance for decision-makers to engage with and align their thinking, decisions and actions with these fundamental principles of regenerative development.

\section{Methodology}

The development of the decision-making framework presented in this paper is primarily built upon the evidence of a qualitative case study investigation into the decision-making approaches of four precincts in Australia that are aligned with regenerative development ideas, processes and aspirations [21]. The qualitative methodological approach of this study is presented in this section across four key areas: (1) the analysis framework used to guide and scope this case study investigation; (2) the data collection and thematic analysis methods used to generate key findings as a set of core and supporting decision-making themes with identified correlations between them; (3) a brief overview of the four case study precincts and how they were identified; and (4) the set of methods, informed by a review of existing regenerative frameworks and tools, that were established to guide how these case study key findings could be structured and represented in the decision-making framework.

\subsection{An Analysis Framework to Investigate Decision-Making in Regenerative Precinct Development}

Figure 1 presents the analysis framework developed to guide and scope this qualitative case study investigation of decision-making in regenerative precinct developments, which is a visual representation of four key elements. Firstly, it seeks to understand the decisionmaking approach required to align with the five fundamental principles of regenerative development presented in Section 2. This was to ensure this qualitative investigation was aligned with the core ideas, processes and aspirations of regenerative development. Secondly, it defined two primary analysis categories-(1) what are the key processes and decisions enabling a precinct to achieve its positive value adding potential; and (2) what are the key factors that can improve or limit their effectiveness (Figure 1) -with associated sub-categories to provide a more tangible scope to investigate what and how decisions are made in alignment with these five fundamental principles. The primary analysis categories provided an effective way to organize and generate the key findings of this study, which is discussed below in Section 3.2. Their associated sub-categories were informed by a review of key literature related to regenerative development (e.g., [12]) and collective decision-making studies (e.g., [27]). 


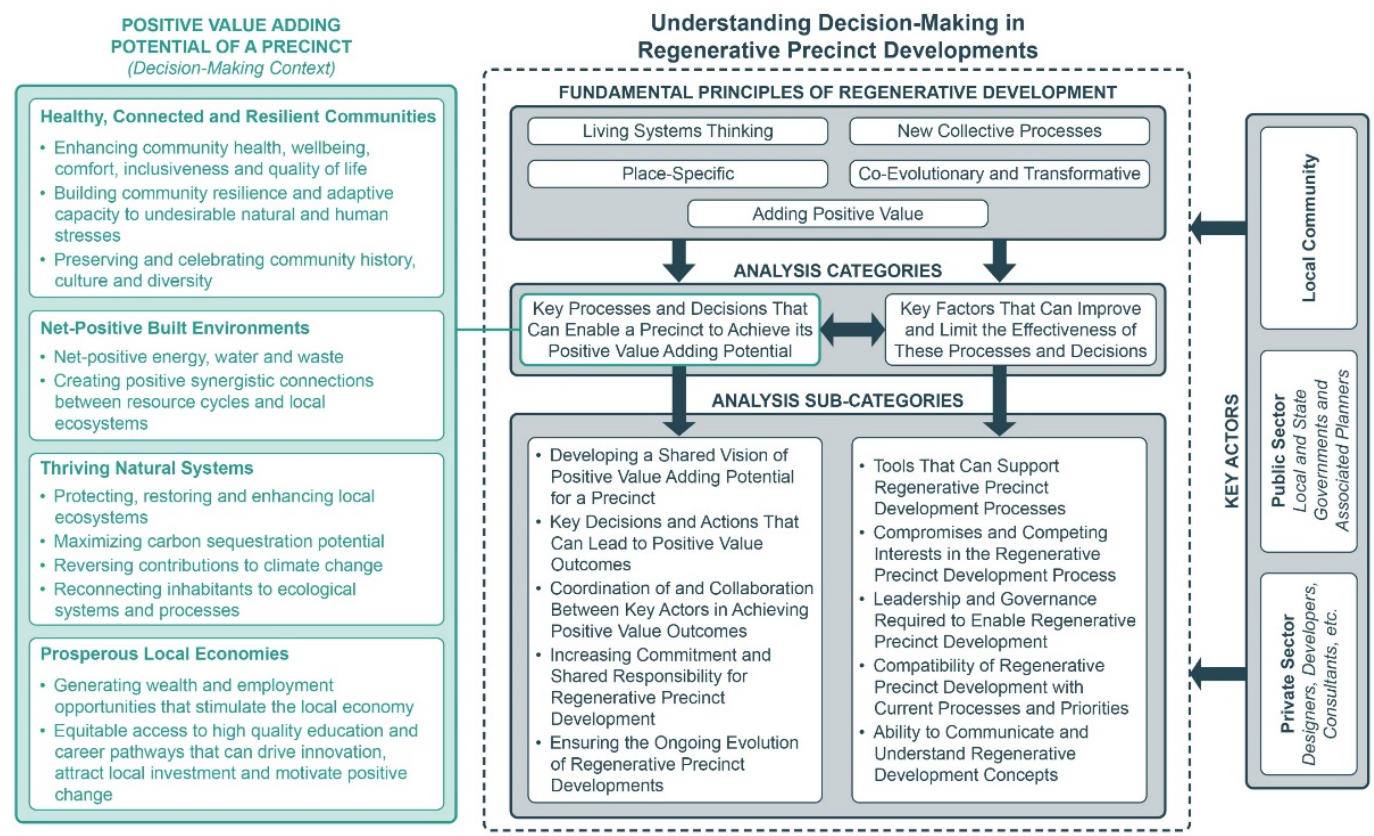

Figure 1. The analysis framework guiding the qualitative case study investigation of decision-making in regenerative precinct developments. Source: authors.

Thirdly, the analysis framework defines a scope of what a precinct's positive value adding potential could be across four key areas shown in green in Figure 1. This scope was informed by some of the key regenerative frameworks and tools (see Section 3.4) and are only presented as broad examples to provide a more robust decision-making context to investigate and to guide the identification of the case study precincts discussed below in Section 3.3. As such, they should not be treated as an exclusive or comprehensive set of targets as the specific positive value adding potential of a precinct is something that is collectively discovered in response to place-specific opportunities and challenges. Finally, it defines the key actors who are individually and collectively making these decisions. This not only involves the typical private and public sector actors shown in Figure 1 but non-traditional ones such as ecologists, artists, sociologists, historians and educators. The scope of key actors involved was not limited as this could vary drastically for different projects.

\subsection{Data Collection and Thematic Analysis Methods}

The qualitative case study investigation used four key data collection methods which are informed by and aligned with the most commonly used methods for case study research defined by [28]. Firstly, a series of in-depth semi-structured interviews were conducted with key decision-makers for the case study precincts. These interviews were approximately one hour each and were directly guided by the analysis categories and sub-categories defined by the analysis framework (Figure 1). Five in-depth interviews were conducted online throughout 2020 (due to COVID-19), and these were complemented with an additional six more informal phone conversations. Secondly, data were collected through direct observational evidence to provide a first-hand understanding of how decisions were made collectively throughout the precinct development process [28]. This observational data were collected through shadowing a range of design meetings, discussions and events for the case study precincts where possible. Thirdly, data were collected through online resources, which included key documentation for the case study precincts (e.g., project reports, planning documentation, community engagement reports, online articles, etc.), and online activities such as webinars and radio interviews directly related to the case study precincts. Finally, data were collected through peer-reviewed publications in existing literature that were directly related to the case study precincts. Having several sources of 
evidence enabled the triangulation of data to corroborate and strengthen the key findings for each case study precinct from multiple sources [28].

These four data collection methods created an evidence base for regenerative precinct development which was then analyzed using a thematic analysis method (Figure 2), which was identified as an appropriate method as it enabled the underlying assumptions, ideas and context of what was explicitly stated in the case study evidence to emerge [29]. Using NVivo 12, the case study evidence base was first broken down into smaller fragments to create meaningful concept groupings that were relevant to the overall research question of this study [30,31]. These initial concept groupings were both descriptive and interpretive, meaning that some were closely related the content of the case study evidence and others were related to what underpinned the semantic surface of this evidence [30]. Hierarchical arrays were then used to identify and structure patterns and higher-order meaning from these initial concept groupings [31]. This firstly involved generating a set of level 1 themes from clustering and reordering specific concept groupings. A set of core and supporting themes were then established from reorganizing and analyzing the level 1 themes to respond directly to the two primary analysis categories defined by the analysis framework presented in Section 3.1 (Figure 2). This process of identifying patterns across the level 1 themes also enabled the identification of correlations between the core and supporting decision-making themes. An overview of the key findings from this case study investigation, presented as the core and supporting decision-making themes and their correlations, is given below in Section 4.

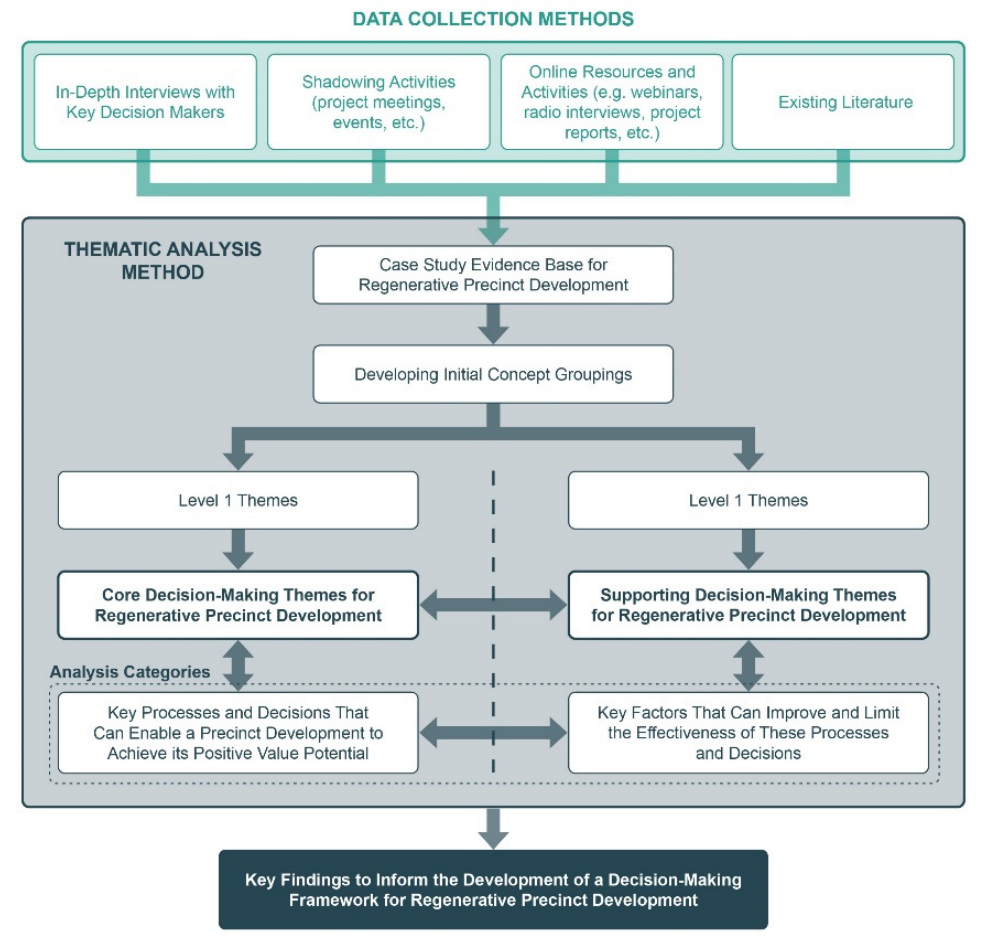

Figure 2. Data collection and thematic analysis methods. Source: authors.

\subsection{Case Study Precincts}

Four case study precincts across Australia were used to investigate and understand decision-making in regenerative precinct developments. These four case study precincts were identified based on their alignment with the five fundamental principles of regenerative development and the scope of a precinct's positive value adding potential defined by the analysis framework (Figure 1). They were also identified across different precinct development contexts and across different stages throughout the development process to ensure a wider range of decision-making opportunities and challenges could be investigated. A brief overview of the four case study precincts is given below. 
Case study precinct 1: NunDuk Spa Retreat (NSR). NSR is a proposed 9.7 ha luxury spa retreat on Lake Wellington, approximately $216 \mathrm{~km}$ east of Melbourne, Australia (Figure 3). It was one of the first projects in Australia to implement a regenerative development process, primarily enabled through the use of the LENSES Framework in its concept development phase [32]. NSR aims to actively reverse the ecological degradation from salt incursion into Lake Wellington through its development and seeks to be entirely water, energy and waste self-sufficient. Its initial vision was to become a master planned regional community but has since evolved to a smaller, tourism-based development in response to political, financial and practical considerations.

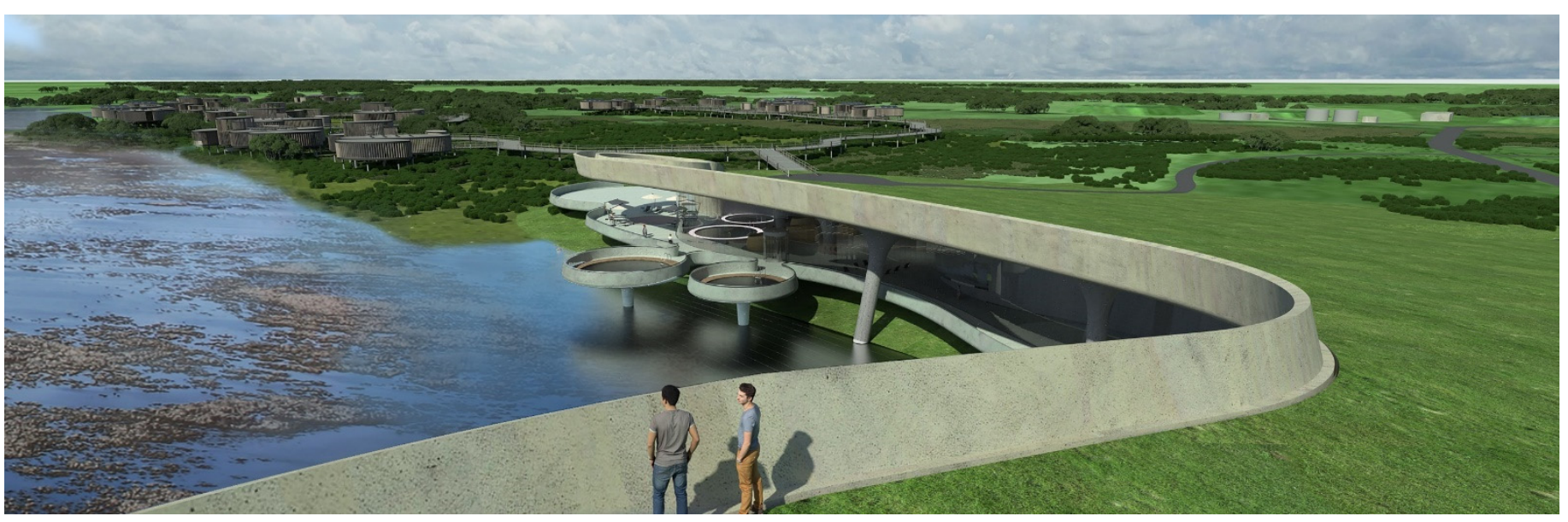

Figure 3. Proposed NunDuk Spa Retreat development on the shores of Lake Wellington in Victoria, Australia. Reproduced with permission from Alfano Studio Architects.

Case study precinct 2: East Village at Knutsford (EVK). EVK is a 1.5 ha urban residential infill development currently under construction just outside of Fremantle in Western Australia (Figure 4). It aims to demonstrate an innovative and commercially viable example of sustainable urbanism [33]. EVK aspires to become a net-zero energy development and empowers the inhabitants of its 36 townhouses to be collectively responsible for its shared infrastructure, which includes an Australian first shared battery that allows real-time energy trading between households and a battery operator using blockchain.

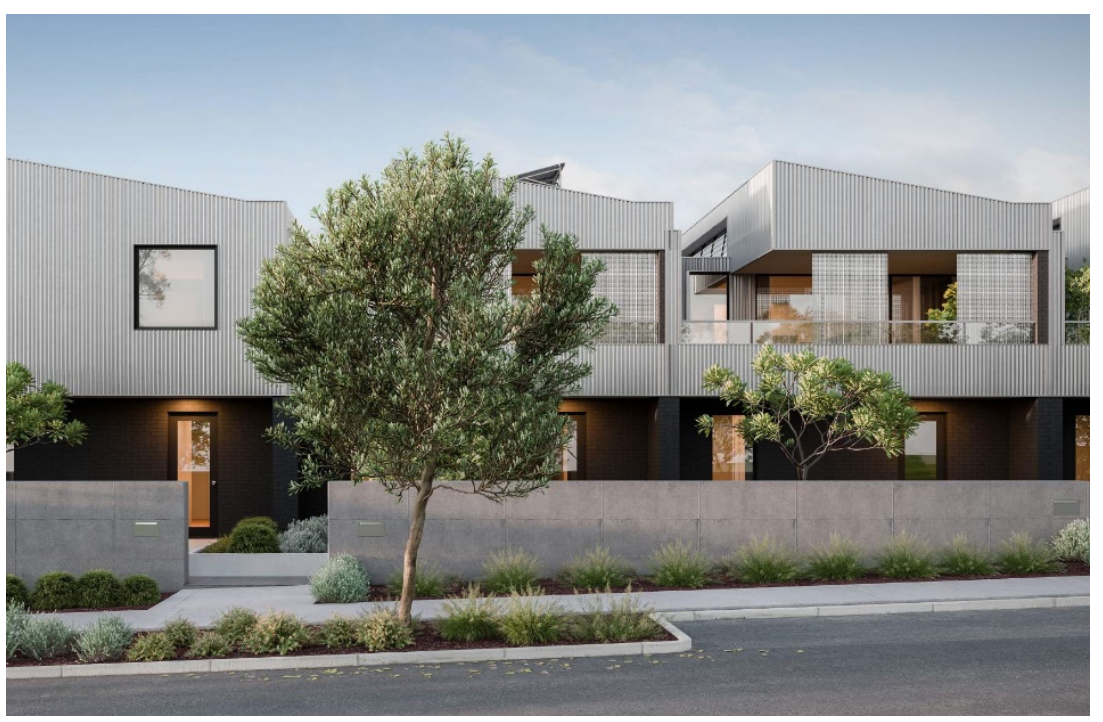

Figure 4. Proposed townhouses for the East Village at Knutsford development. Reproduced with permission from DevelopmentWA. 
Case study precinct 3: Burwood Brickworks (BB). BB is a now completed shopping centre within a 20.5 ha urban mixed-use precinct in Melbourne, Australia (Figure 5). This former brickworks site is on track to become the world's first shopping centre to achieve full Living Building Challenge certification. BB actively celebrates its Wurundjeri culture and history to connect its visitors to ancient stories of place through its design. It also integrates Australia's largest urban rooftop farm which provides fresh produce for local restaurants and offers an educational experience for anyone that wants to grow their own food.

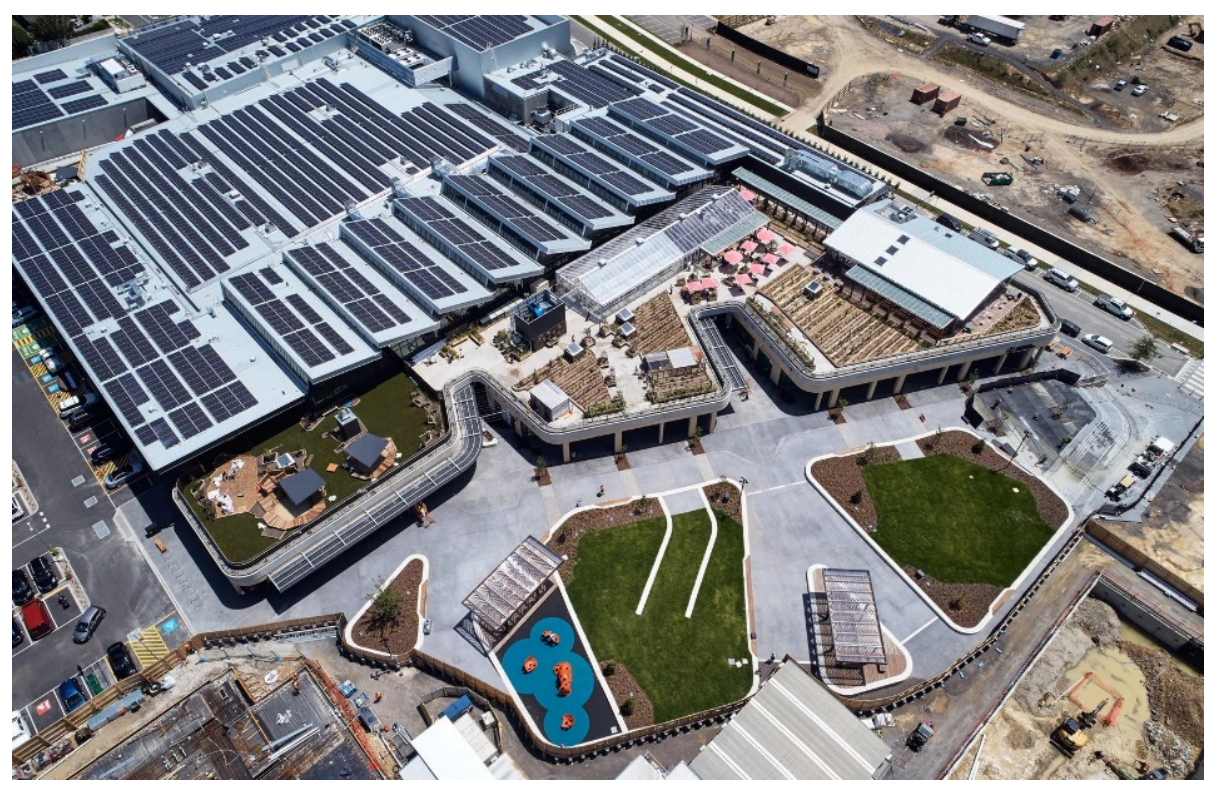

Figure 5. Burwood Brickworks Shopping Centre showing its 1MW solar PV array and rooftop urban farm. Reproduced with permission from Hacer Group.

Case study precinct 4: Narara Ecovillage (NEV). NEV is a 64 ha community owned and operated development currently under construction on the Central Coast of New South Wales, approximately $87 \mathrm{~km}$ north of Sydney, Australia (Figure 6). It aims to be a demonstration zero carbon village by showcasing its innovative and sustainable features and processes through various research, educational and outreach initiatives. NEV is also the largest development in Australia that uses sociocracy (or dynamic governance) on a daily basis to support its decision-making and organizational structure.

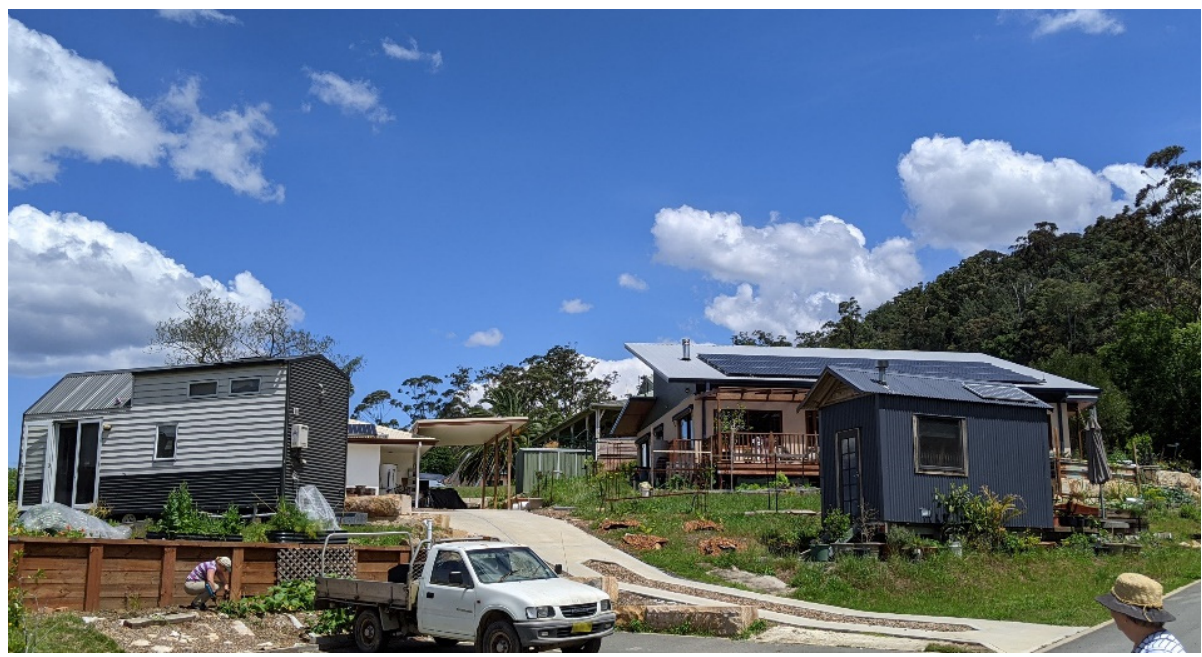

Figure 6. Diverse housing within Narara Ecovillage's stage 1 development. Source: authors. 


\subsection{Developing the Decision-Making Framework}

The decision-making framework for regenerative precinct development is primarily established from the key findings of this qualitative case study investigation. However, to identify how to effectively organize and structure these key findings into a coherent decision-making framework, a review of key existing regenerative frameworks and tools was conducted. This review investigated the key features, structure, processes, purpose and practical applications (where relevant) of the regenerative frameworks and tools presented in Table 1.

Table 1. Key regenerative frameworks and tools reviewed.

\begin{tabular}{cc}
\hline Regenerative Framework/Tool & Source \\
\hline Regenesis Framework and Methodology & {$[7,12]$} \\
LENSES Framework & {$[19,34]$} \\
Perkins + Will Framework & {$[24]$} \\
Eco-Positive Design Review & {$[20]$} \\
STARfish Tool & {$[20]$} \\
Regenerative Development Evaluation Tool & {$[35]$} \\
Living Building and Community Challenges & {$[36,37]$} \\
One Planet Living & {$[38]$} \\
REGEN Tool & {$[39]$} \\
Strategies for Designing Urban Ecosystem Services & {$[40]$} \\
\hline
\end{tabular}

Despite the diversity of approaches, this review highlighted the need for a regenerative framework that focuses specifically on decision-making and its associated challenges and opportunities throughout the development process. Importantly, it also informed the identification of key methods that could guide how this regenerative decision-making framework could be presented. As a result, three interconnected methods were identified to support how the key findings from the case study investigation were organized and structured into the decision-making framework:

- Expanding not prescribing. Encourage divergent and whole systems thinking to discover potential synergies and expand possible outcomes rather than prescribe a list of decision alternatives to compare and optimize;

- Questions not solutions. Ask challenging questions to enable this thinking rather than develop reactive solutions to superficial problems;

- Pluralistic not dualistic. Despite the obvious paradox of explaining these methods, promote multiple design and development pathways and discourage yes/no, either/or, right/wrong questions and decisions.

\section{Key Findings for Decision-Making in Regenerative Precinct Developments}

This section provides an overview of the key findings from the qualitative case study investigation into the decision-making approaches of regenerative precinct developments. A more detailed discussion of these key findings and how they were generated is presented in an additional paper by the authors [21]. The purpose of their inclusion in this paper is to demonstrate how these key findings informed and enabled the development of the decision-making framework for regenerative precinct development, presented in Section 5. The key findings of this qualitative case study investigation were generated using the thematic analysis method outlined in Section 3.2 and are presented below as a set of core and supporting decision-making themes with identified correlations between them. This section provides a high-level overview of the core and supporting decision-making themes that were generated and discusses some of the key concepts within each theme, supported by tangible examples from the case study evidence, that were relevant to informing the development of the decision-making framework for regenerative precinct development. 


\subsection{Core Decision-Making Themes}

Although the case study precincts exhibited a unique set of decisions and processes specific to their place, common ideas and concepts were identified using the thematic analysis method presented in Section 3.2 to facilitate the development of four core decisionmaking themes. Aligned with the first primary analysis category guiding this qualitative case study investigation (see Section 3.1), these were identified as the key processes and decisions that enabled the case study precincts to achieve their positive value adding potential. The four core decision-making themes are:

- Building the collective vision of potential. Decisions and actions to discover a clear and shared vision of positive value adding potential for a precinct;

- Aligning with and implementing the vision. Aligning decisions and actions with implementing the precinct's collective vision of positive value adding potential;

- Expanding shared responsibility for the vision. Decisions and actions that expand a shared responsibility for the precinct to ensure its collective vision of positive value adding potential is sustained into the future;

- Positive transformations enabled by the vision. The positive transformations that are enabled from the processes of building, implementing and sharing responsibility for the precinct's collective vision of positive value adding potential.

At the heart of each of these core decision-making themes, and therefore central to the development of the decision-making framework, is a collective vision of positive value adding potential for the precinct. Firstly, the case study evidence emphasized the importance of establishing a precinct's vision of positive value adding potential through a collective process of discovery with a diverse range of key actors in response to placespecific opportunities and challenges. This resulted in a significant departure from typical decision-making in the initial precinct development stages as to what decisions were made, how and by who. For example, part of NSR's initial vision was for a small regional town around the creation of waterways. This was established in response to its unique location on the shores of Lake Wellington through the collective efforts of a diverse range of actors which included a sea grass ecologist, fish ecosystems scientist, hydrologist, geomorphologist and carbon sequestration experts [32].

Secondly, all subsequent decisions, typically related to the development's detailed design and construction, for the case study precincts were aligned with implementing this collective vision of positive value adding potential. This was primarily enabled by an immersive, transparent and collaborative decision-making approach involving key actors across public and private sectors and the local community. For example, BB maintained immersive and transparent relationships with its numerous retail tenants to encourage, enable and empower them to meet the stringent Living Building Challenge requirements when designing and implementing their shop fit outs, especially in relation to material choices.

Thirdly, the case studies all prioritized decisions to expand and encourage collective responsibility for the precinct and its vision of potential to ensure that the aspiration and capacity to add positive value continues beyond the project's physical completion. The case study evidence showed that these decisions need not be limited to the final development stages and that this shared responsibility can be an effective in addressing competing interests. For example, a key decision-maker for NEV was able to empower and inspire prospective ecovillage members to be actively involved in the future of the project by giving them a first-hand experience of its place even before the land was acquired. These in-person events played a critical role in NEV's ability to subsequently self-fund $5 \$$ million from these community members to purchase the site.

Finally, the case study precincts provided evidence of positive transformations for individuals and organizations enabled by their involvement in the decision-making processes of establishing, implementing and sharing responsibility for the precinct's collective vision of positive value adding potential. These positive transformations manifested in the changes of how decision-makers will think, act and make decisions in their future pro- 
fessional and personal lives. For example, decision-makers across all case study precincts stated that their involvement in the project has built their confidence and knowledge to take forward into future projects. At a personal level, one BB decision-maker has now changed the way they view and manage their household waste from their experience with the rigorous requirements of the Living Building Challenge.

\subsection{Supporting Decision-Making Themes}

Similarly, the decision-making approaches of the case study precincts were all influenced by unique, diverse and place-specific factors. However, four supporting decisionmaking themes were developed from identifying the common ideas and concepts emerging from the case study evidence using the thematic analysis method presented in Section 3.2. Aligned with the second primary analysis category guiding this qualitative case study investigation (see Section 3.1), these were identified as the key factors improving or limiting the decision-making effectiveness of the case study precincts. The four supporting decision-making themes are:

- Financial, regulatory and design compromises. The compromises made throughout the development process that are required to enable the implementation of regenerative precinct developments;

- Leadership and governance. The leadership and governance that is required to support and enable regenerative precinct developments;

- Supporting design tools and frameworks. The tools and frameworks that are used to support and guide the implementation of regenerative development ideas and processes;

- Communicating regenerative development. How regenerative development ideas, processes and aspirations are communicated to others.

Examples of key findings relevant to the development of the decision-making framework for each supporting decision-making theme are briefly discussed here. Firstly, many of the compromises made to implement the case study precincts were in response to unforeseen and unavoidable circumstances. However, decision-makers demonstrated an ability to see these typically short-term compromises not as negative outcomes, but as opportunities to ensure and enable positive value outcomes in the long-term. For example, part of NEV's ambition was to enable diverse housing options and support small local businesses within the village. However, due to local council requirements, stage one of NEV's development was compromised to be single residential $550 \mathrm{~m}^{2}$ lots, which meant many could not afford to live in the ecovillage. This led to some ecovillage members creatively finding ways to share a single title that is not reliant on dual occupancy zoning, which is now being formally encouraged for the second stage of development to improve NEV's affordability and housing diversity for the future.

Secondly, the case studies showed that multiple governance structures were effective at enabling the co-creative processes required to achieve positive value outcomes. The case study evidence emphasized that government-led, developer-led and community-led development models all have the potential to create regenerative precincts, but each comes with unique decision-making challenges and opportunities. For example, BB showed that a large private developer can implement a project that adds positive value, enabled through the Living Building Challenge, and still make a financial return in a retail context. However, this required the developer to play a central role in motivating and inspiring a co-creative effort across a wide range of actors in the built environment industry as well as for thirty individual retail tenants.

Thirdly, the supporting design tools and frameworks used by the case study precincts were effective at guiding and structuring the co-creative and transdisciplinary approach that is required for regenerative precinct developments. Importantly, the use of these tools also helped to build new capabilities for individuals and organizations as well as encouraged them to step into a new role as stewards to ensure the precinct and its aspirations to add positive value are sustained into the future. For example, using the LENSES Framework facilitated positive changes in the business values and priorities of 
NSR's small-scale developer which was shown through their commitment to ensuring the long-term success of this project- "You don't just get a return for year one, you're building a return that effectively compounds over time".

Finally, the case study precincts demonstrated the importance of how they communicated their project both as a form of advocacy for regenerative development practices and as an effective way to address competing interests. For example, EVK's development as an 'Innovation Through Demonstration' project [41]—which means it is developed as a living laboratory to design, test and learn from innovative approaches and technologies-has enabled the project to generate widespread awareness and advocacy for regenerative development practices within the built environment industry both nationally and internationally.

\subsection{Correlations between the Core and Supporting Decision-Making Themes}

Correlations between the core and supporting decision-making themes were also generated from the case study evidence using the thematic analysis method presented in Section 3.2. These correlations map the specific impacts the supporting themes had on the decision-making effectiveness of the core processes and decisions. A total of 17 major and 11 minor correlations were identified between the core and supporting decisionmaking themes based on the amount of supporting evidence from the case study precincts, which have been presented in more detail by an additional paper by the authors [21]. For example, a major correlation was identified between a precinct's leadership and governance approach and expanding a shared responsibility for its collective vision of positive value adding potential. More specifically, NEV's highly transparent and collaborative sociocratic governance and decision-making approach was found to be effective at empowering the ecovillage members to be directly involved and collectively responsible for the future of the precinct. These major correlations informed how the decision-making framework for regenerative precinct development provides guidance in relation to the supporting decision-making themes, which is discussed further in Section 5.3.

\section{A Decision-Making Framework for Regenerative Precinct Development}

This section presents a novel decision-making framework for regenerative precinct development that is formed directly from the key findings of this case study investigation. It is therefore developed as an evidence-based framework that seeks to guide and support decision-making throughout the regenerative precinct development process. It is a visual guiding framework that is developed from the key methods described in Section 3.4. It comprises one primary diagram to present its key elements and theoretical basis, as well as five supplementary diagrams to provide more specific guidance for the core and supporting themes, presented in Section 4, through a series of challenging questions for decision-makers to consider. The decision-making framework provides theoretical and practical guidance for decision-makers to align their thinking, decisions and actions with the fundamental principles of regenerative development throughout the precinct development process.

\subsection{Key Elements of the Decision-Making Framework}

Figure 7 presents the decision-making framework for regenerative precinct development. This primary diagram shows the framework's overall structure and key elements as well as its theoretical basis. It is a visual representation of (1) the importance of a precinct's collective vision of positive value adding potential; (2) the five fundamental principles of regenerative development presented in Section 2; (3) the core decision-making themes generated from the case study evidence (Section 4.1); and (4) the supporting decision-making themes generated from the case study evidence (Section 4.2). 


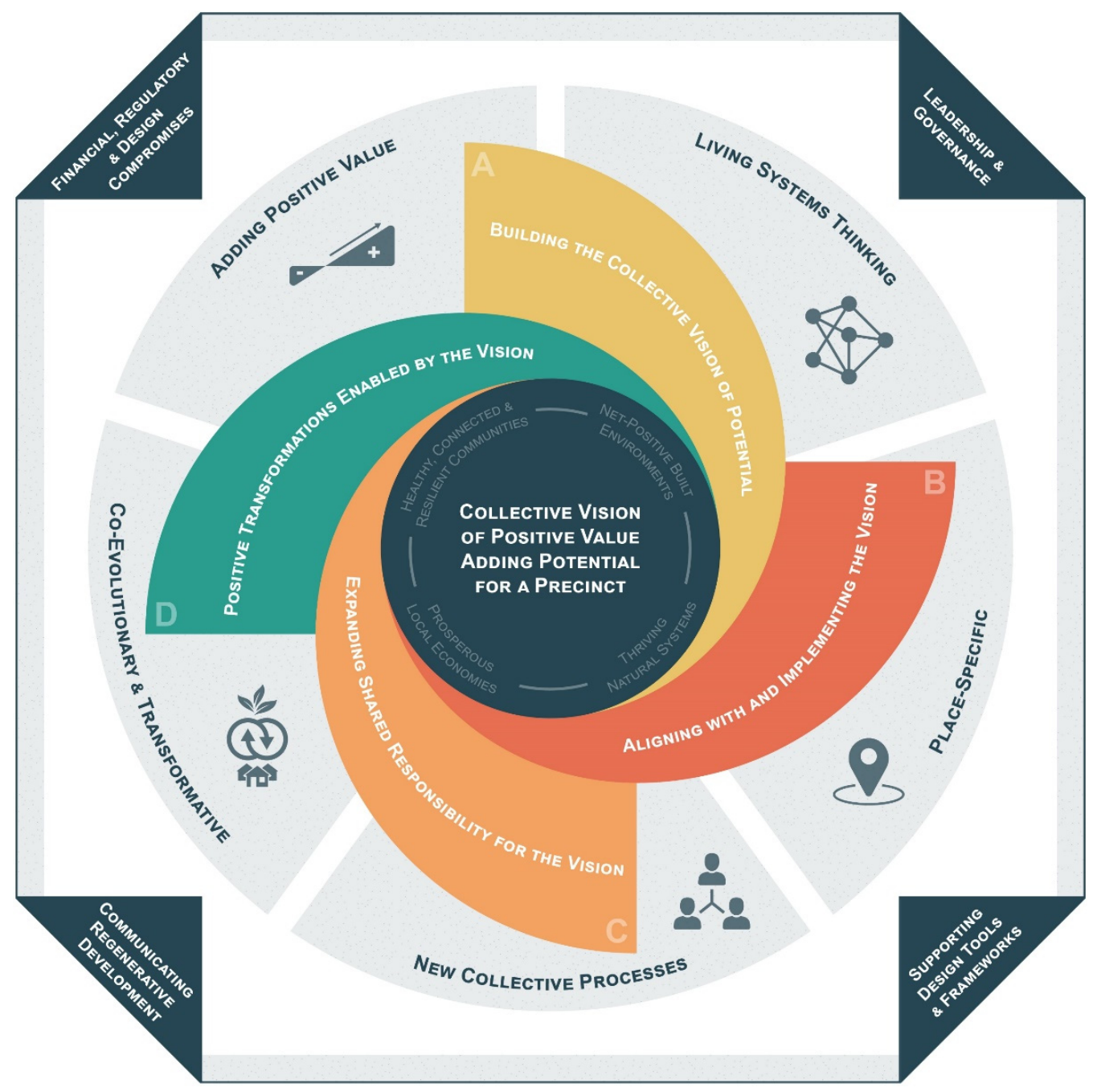

Figure 7. The decision-making framework for regenerative precinct development. Source: authors.

The first key element of the decision-making framework is a precinct's collective vision of positive value adding potential. As mentioned previously, this collective vision of potential is critically important to the decisions and actions that enabled the case study precincts to have a positive value adding role. This collective vision of positive value adding potential is therefore the central guiding element of the decision-making framework and is visually represented by the dark blue inner circle in Figure 7. A broad scope for a precinct's positive value adding potential is also defined by the framework's inner circle, which relates to the four key areas defined by the analysis framework (Figure 1).

The five fundamental principles of regenerative development defined by Section 2livings systems thinking, place-specific, new collective processes, co-evolutionary and transformative and adding positive value-form the second key element of the framework. These five principles are visually represented by the outer circle of the framework in Figure 7. Each principle is split into its own wedge within the outer circle to structure the specific guiding questions for each core decision-making theme, which will be discussed below in Section 5.2. Including the five principles in the framework ensures that decision-makers align their thinking, decisions and actions throughout the precinct development process with the fundamental ideas, processes and aspirations of regenerative development, which are defined by these principles.

The core decision-making themes that were generated from the case study investigation are the third key element of the framework. The core themes are visually represented in the decision-making framework by the four coloured spirals denoted A, B, C and D in 
Figure 7. A spiral structure is used as a visual reference to prompt divergent and whole systems thinking for decision-makers to expand and discover possible decision alternatives and outcomes. As the core decision-making themes were defined as the key processes and decisions enabling the case study precincts to achieve their positive value adding potential, they are presented as the four primary domains in which decision-making guidance is provided for in the framework. Guidance for the core decision-making themes will be discussed below in Section 5.2.

The supporting decision-making themes that were generated from the case study investigation are the fourth and final key feature of the framework. The four supporting decision-making themes are visually represented by the dark blue arrows in the outermost layer of the framework in Figure 7. These four supporting themes represent the key factors identified from the case study investigation that influenced the effectiveness of the core decisions and processes. As such, they are visually represented as arrows pointing inwards to signify an influencing force, but it is important to note that they can have both a positive and negative influence on decision-making. Guidance for the supporting decision-making themes will be discussed below in Section 5.3.

\subsection{Decision-Making Guidance for the Core Themes}

The decision-making framework for regenerative precinct development provides more specific guidance for each core decision-making theme through four detailed diagrams. These supplementary diagrams pose challenging questions for decision-makers to consider for each core theme. The questions are based on case study evidence from the key concepts and level 1 themes that the core decision-making themes were developed from. As it is an evidence-based framework, these questions should not be a treated as an exclusive or comprehensive list. Rather, they are representative of the types of questions emerging from the case study evidence for decision-makers to consider throughout the regenerative precinct development process. Furthermore, none of the questions are posed to prompt yes/no or right/wrong answers to encourage decision-makers to collectively discover and expand potential development pathways and outcomes.

The questions for each core theme are structured in alignment with the five fundamental principles of regenerative development presented in Figure 7. This is to ensure that the precinct development process considers decisions and actions that respond to each fundamental principle as well as the interdependencies between them. The specific guiding questions for core decision-making themes $\mathrm{A}$ and $\mathrm{B}$ will be explained in more detail below as examples, while the questions for core themes $C$ and $D$ are shown in Appendix A.

\subsubsection{Core Decision-Making Theme A: Building the Collective Vision of Potential}

Figure 8 presents the specific guiding questions for core theme a established by the decision-making framework. These are the questions that are generated from the case study evidence to support decision-makers in discovering and developing a precinct's collective vision of positive value adding potential during the earlier development stages. An example question is discussed below to highlight how it has been established from the case study evidence and what it is prompting decision-makers to consider. 


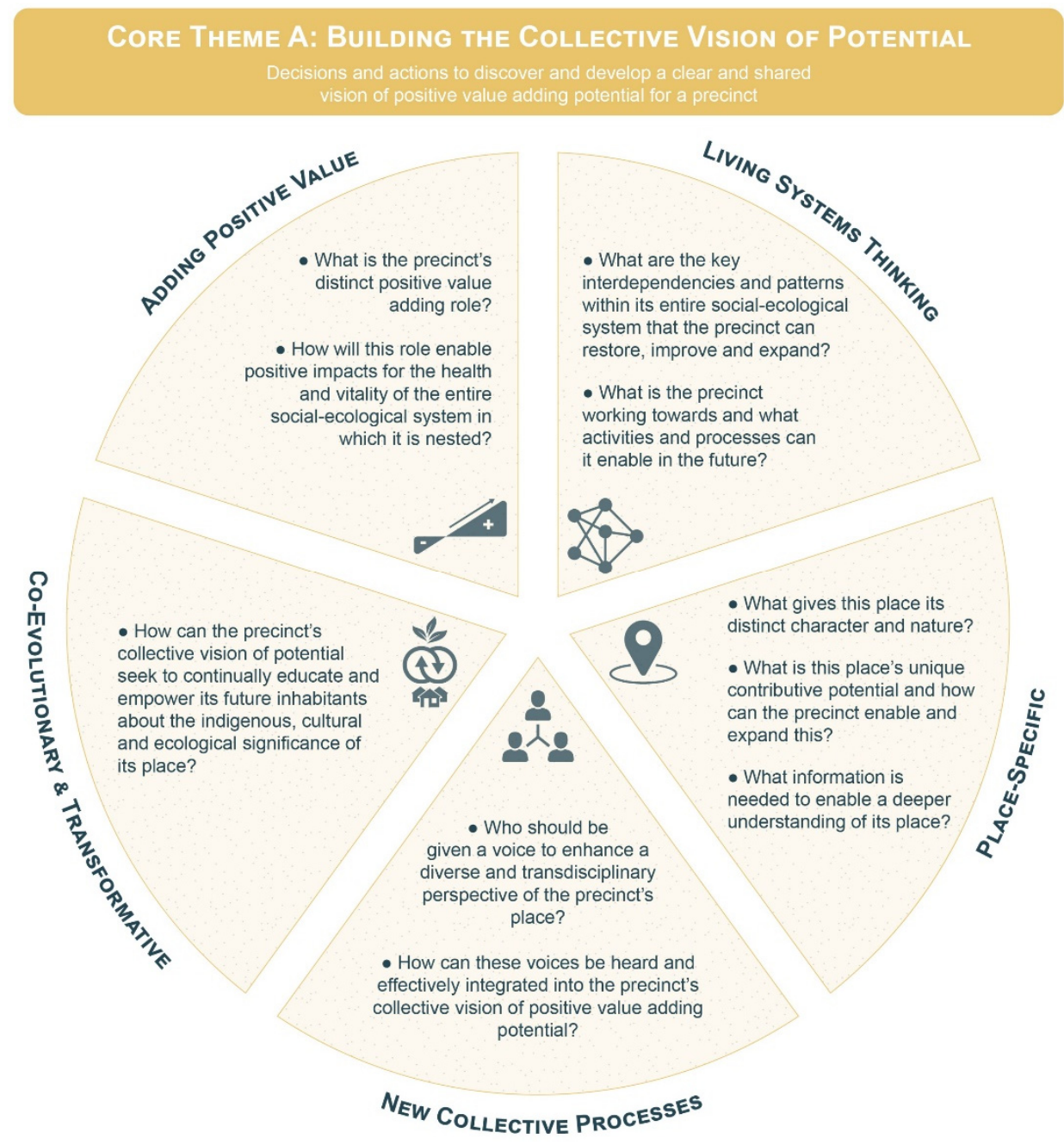

Figure 8. Decision-making guidance for developing a precinct's collective vision of positive value adding potential. Source: authors.

The first question of the living systems thinking wedge in Figure 8-what are the key interdependencies and patterns within the entire social-ecological system that the precinct can restore, improve and expand?-seeks to prompt decision-makers to position a precinct as an integral and inseparable part of the larger social-ecological system and recognize that it has the potential to influence the ongoing health and vitality of this system. By taking a big picture view of a precinct and its surroundings, decision-makers are more likely to be able to identify the key patterns and system interdependencies of the whole system it is nested within and explore which of these it can restore, improve or expand. This question is informed by decision-makers for the case study precincts demonstrating an ability to think systemically to discover these system interdependencies when developing the collective vision of potential. For example, a NSR decision-maker stated that at the heart of establishing the collective vision for the project to be an entirely self-sufficient development that actively improves its ecologically degraded surroundings was taking "more of a big picture view of looking at what things are actually impacting on other things and seeing the connections that are there that might have been missed from a standard process".

Responding to this question also requires decision-makers to engage with and consider questions categorized by other fundamental principles in Figure 8, which demonstrates the interconnected and holistic decision-making that is required throughout the regenerative precinct development process. For instance, identifying the key patterns and system interdependencies of the larger social-ecological system requires decision-makers to develop 
a profound understanding of the precinct's place and ask what its unique contributive potential is. Decision-makers would then need to consider what information is needed and who should be given a voice to enable a diverse and transdisciplinary understanding of the precinct's place.

This example question highlights the type of guidance the decision-making framework seeks to provide to support decisions and actions in collectively discovering and developing a precinct's vision of positive value adding potential.

\subsubsection{Core Decision-Making Theme B: Aligning with and Implementing the Vision}

Figure 9 presents the specific guiding questions for core theme B established by the decision-making framework. These are the questions that are generated from the case study evidence to support decision-makers in aligning all subsequent decisions and actions, typically associated with a precinct's design, construction and operation, with implementing its collective vision of positive value adding potential. Similarly, an example question is discussed below to highlight the type of decision-making guidance the framework provides relating to core theme $B$ and how the questions are developed from the case study evidence.

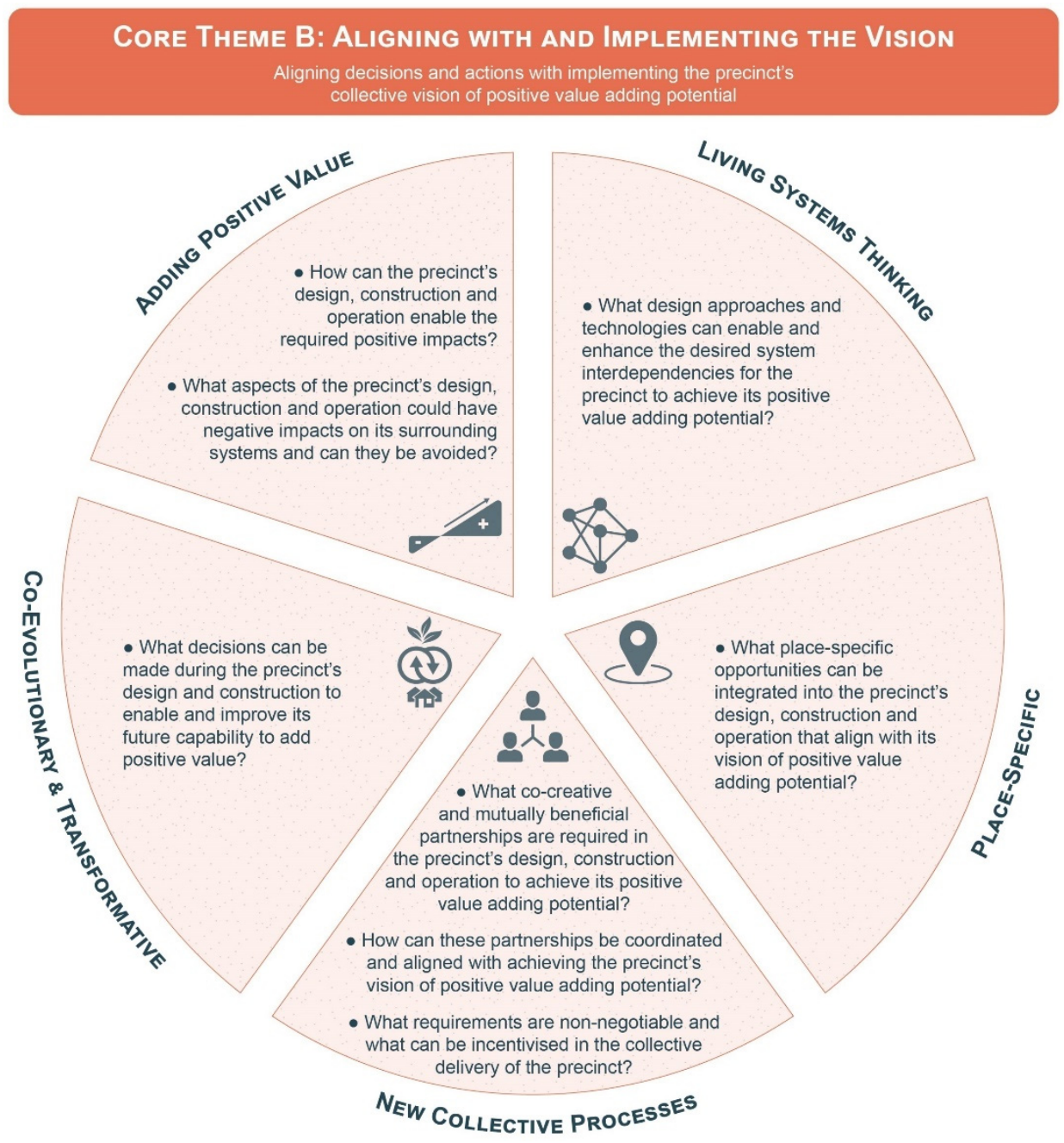

Figure 9. Decision-making guidance for aligning with and implementing a precinct's collective vision of positive value adding potential. Source: authors.

Using the example of the place-specific wedge in Figure 9, the question-what placespecific opportunities can be integrated into the precinct's design, construction and operation that align with its vision of positive value adding potential? - seeks to prompt decision-makers to consider what unique aspects from the developed understanding of 
a precinct's place can be conceptualized and leveraged to enable its design, construction and operation to align with and exemplify its collective vision of positive value adding potential. In doing so, this question ensures that developing a profound understanding of a precinct's place is not simply a box-ticking exercise, but something that significantly informs and guides its overall vision and subsequent implementation. Similarly, responding to this question also prompts decision-makers to engage with and consider questions categorized by other fundamental principles in Figure 9, such as what design approaches and technologies can then enable the implementation of these place-specific opportunities.

A key example that informed the development of this question from the case study evidence was through the significant cultural and historical learnings that BB's decisionmakers undertook to deepen their understanding of the meaning and importance of its place. Firstly, this was shown through an investigation into the site's former function as a brickworks. This resulted in not only the naming of the precinct but enabled decisionmakers to track down bricks that were made on site in the 1970s and reuse them as part of the shopping centre's façade. Secondly, this was shown through the awareness, acknowledgement and celebration of the Indigenous history and significance of this place for the Wurundjeri people of the Kulin nation. Opportunities enabled by this then emerged to use the design of the shopping centre to educate visitors about its cultural and historical importance. BB's expansive ceiling designed by a local Indigenous artist (Figure 10) and the visitor experience upon entering are evidence of how this was achieved- "when you walk in through the lobby you get this soundscape of the forest and the smellscape of burning eucalyptus, which is part of the welcoming for the Wurundjeri people".

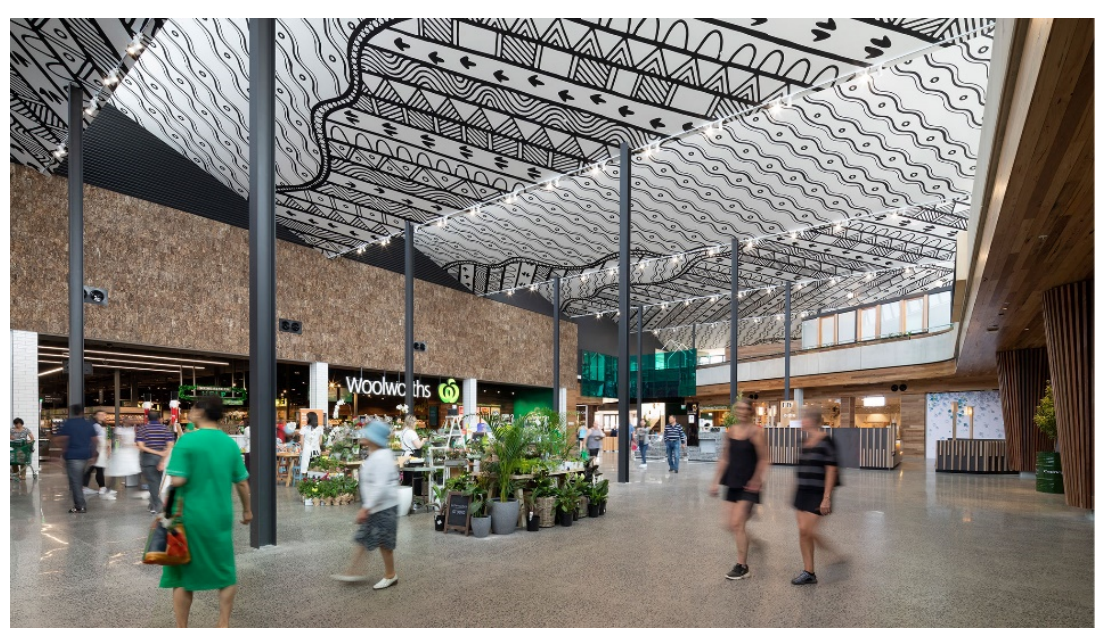

Figure 10. Mandy Nicholson's artwork spans across the ceiling of Burwood Brickworks Shopping Centre and reflects different elements of Wurundjeri culture. Reproduced with permission from Frasers Property.

\subsection{Decision-Making Guidance for the Supporting Themes}

The decision-making framework for regenerative precinct development also provides more specific guidance for the supporting decision-making themes through a series of challenging questions presented in a fifth supplementary diagram (Figure 11). These questions are informed by the case study evidence from the key concepts and level 1 themes that the supporting decision-making themes were developed from. They provide decision-making guidance related to the key factors that could influence the key processes and decisions defined by the core decision-making themes. To visually represent this, a spiral legend is provided for each supporting theme to indicate its major correlations with the core themes. Each question under the supporting themes is then colour-coded to enable decision-makers to clearly visualize which core theme it has the potential to influence the effectiveness of (Figure 11). For example, a major correlation that emerged from the case study evidence was between the design tools and frameworks used in the decision-making 
process, such as the LENSES Framework, and their ability to create positive and lasting changes in how individuals and organizations will make decisions in the future. This is reflected by the question in the bottom-right quadrant of Figure 11 that is colour-coded green to indicate a correlation with core theme D.

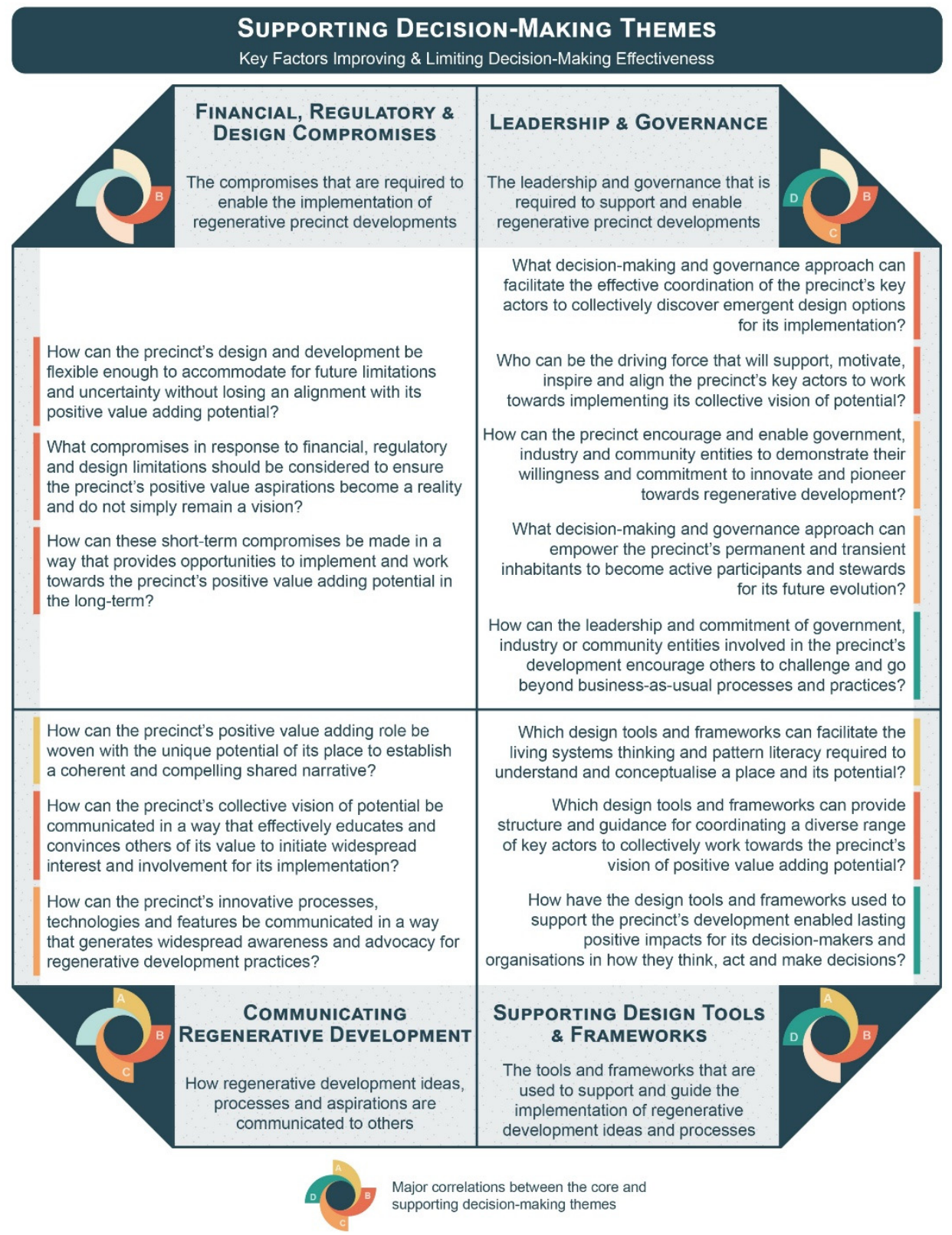

Figure 11. Decision-making guidance for the key factors that can improve and limit decision-making effectiveness. Source: authors.

It is worth noting again that these are representative questions that emerged from the case study evidence and should not be seen as an exclusive or comprehensive list. Two examples of guiding questions from Figure 11 will be discussed below to highlight the type of guidance the decision-making framework provides for the supporting themes and how the questions are developed from the case study evidence.

Firstly, under the financial, regulatory and design compromises, the question-how can these short-term compromises be made in a way that provides opportunities to implement and work towards the precinct's positive value adding potential in the long-term?seeks to prompt decision-makers to consider how unavoidable compromises to ensure a 
precinct's implementation can be reframed from a negative outcome to a positive opportunity for the future. In other words, this question encourages decision-makers to identify the potential benefits of making short-term compromises to enable the implementation of positive value outcomes in the long-term. This guiding question is therefore intended to support decisions made that are primarily made during the design and construction of a precinct and is colour-coded red in Figure 11 to reflect its correlation to core theme B.

A key example from the case study evidence that informed the development of this question was through EVK's response to current regulatory barriers. EVK has an innovative embedded network that uses a $670 \mathrm{kWh}$ shared battery to enable real-time energy trading between its 36 townhouses and a battery operator using blockchain. Also within this precinct is an additional two apartment sites. A proposal to extend this innovative embedded network to these apartments was rejected based on current energy regulations in Australia. However, a decision was made in the design of this precinct to easily allow for this future connection once future energy regulations permit it- "when the battery and the electrical sub-board arrangement was all set up, it was done in such a way that would make the future connection of those other two lots quite straightforward. Even though the regulations didn't support it, you can prepare for it".

Secondly, under the leadership and governance required for regenerative precinct developments, the question-what decision-making and governance approach can empower the precinct's permanent and transient inhabitants to become active participants and stewards for its future evolution?-seeks to prompt decision-makers to consider how they can empower a precinct's inhabitants to become collectively responsible for its future through the way their project is governed and how decisions are made. This guiding question is therefore intended to support decisions made to expand a shared responsibility for a precinct (core theme C) and is colour-coded orange in Figure 11 accordingly.

This question was informed by the case study precincts through their various governance models and decision-making methods, each of which was shown to be effective at enabling positive value outcomes. However, each of these approaches encouraged and facilitated collaborative and transdisciplinary efforts, which were shown to be effective at empowering their inhabitants to play an active role as stewards for the future evolution of the precinct. Most notably, NEV uses sociocracy (or dynamic governance) for its organizational structure and decision-making. This means that rather than an autocratic or democratic decision-making process, decisions are made based on gathering consent (i.e., no disagreement) from all decision-makers before moving forward in a truly collaborative and transparent process [42]. The ecovillage members therefore have a strong sense of collective responsibility for their precinct as they are directly involved in the decision-making processes for its future, where their voices are all heard, respected and valued. This has meant that to date, the toughest decision they have made is the road naming because "there is no right answer and no wrong answer, and there's 200 different opinions and they are all equally valid."

\section{Discussion and Conclusions}

This paper presents the development of a novel decision-making framework that provides evidence-based guidance for decision-makers to align their thinking, decisions and actions with the fundamental principles of regenerative development. The framework aims to reframe decision-making from being an optimization challenge between predetermined technologies or design features, to an ongoing and collective process of discovery that explores and expands the potential ways a precinct can add positive value. Decisions regarding a precinct's design, construction, operation and evolution can then be made from an understanding of the entire social-ecological system and aligned with the precinct's unique contributive role within it to ensure its ongoing vitality and viability. The framework therefore encourages decision-makers to engage with a fundamentally different way of thinking and making decisions, and this is where the potential of the framework emerges to support the transition to regenerative development practices. 
By purposefully posing challenging questions, instead of listing potential solutions, the decision-making framework prompts decision-makers to align how they think, act and make decisions in a more harmonious and less extractive relationship with nature. These questions also invite decision-makers to consider how to encourage, organize and sustain a co-creative process with a diverse range of key actors to work towards a common vision of positive value adding potential. By doing so, the framework reinforces a core value that is central to the transition to regenerative development practices. That enabling the positive outward transformations of a precinct, guided by its collective vision of potential, requires positive inward transformations for the individuals and organizations involved in the process in how they think, act and make decisions. What results is a framework that encourages a significant departure from technology and efficiency-driven decision-making approaches by seeking to redefine what decisions could be made, how they are made and by who throughout the precinct development process.

Adopting this new way of thinking and making decisions is critical to ensuring a liveable, resilient and thriving future. This is because we have the technological, cultural and economic capacity to effectively respond to the global climate emergency. What is urgently needed now is to reframe our efforts in a co-evolutionary partnership with nature, and this requires adopting a new mind, heart and way of being. The framework presented in this paper starts to explore how this can be achieved and supported in the context of decision-making within a precinct development process. By doing so, the framework not only reinforces the necessary paradigm shift that is central to many of the existing regenerative frameworks and tools but provides an important theoretical contribution to how decision-making in the built environment can be understood and approached within a regenerative development context.

\section{Limitations and Future Work}

It is acknowledged that the decision-making framework for regenerative precinct development is established from a relatively small number of case study precincts, which are all within an Australian planning and development context. However, being an evidence-based framework, the intention is to continually expand and improve this first iteration of the framework by collecting and analyzing more evidence from a diverse range of precinct developments aligned with regenerative development ideas, processes and aspirations. The structuring of key ideas and processes provides a solid foundation for this continual improvement, refinement and expansion of the decision-making framework for regenerative precinct development.

A key part of the decision-making framework's continual improvement will be investigating its relevance to different built environment actors and within various planning, governance and geographical contexts. It is hypothesized that the open-ended nature of the questions and themes in the framework as well as its intention to be improved and expanded, will mean that it could be used to support decision-makers outside of an Australian planning and development context. Future work will therefore involve testing and gathering feedback on the decision-making framework from various built environment practitioners.

The intention of this framework was not, nor will not be, to provide a complete list of questions that decision-makers must answer to create regenerative precinct developments. Instead, this framework uses example evidence-based questions to provide a tangible way for decision-makers to organize and align their thinking, decisions and actions with regenerative development. By doing so, the decision-making framework for regenerative precinct development adds to and complements the growing number of frameworks and tools available to support the transition to regenerative development practices in the built environment.

Author Contributions: Conceptualization, W.C., L.D. and D.P.; methodology, W.C. and L.D.; formal analysis, W.C.; investigation, W.C.; data curation, W.C.; writing-original draft preparation, W.C.; writing-review and editing, W.C., L.D. and D.P.; visualization, W.C.; supervision, L.D. and D.P.; 
project administration, W.C., L.D. and D.P. All authors have read and agreed to the published version of the manuscript.

Funding: This work was supported by an Australian Government Research Training Program Scholarship.

Institutional Review Board Statement: The study was conducted according to the guidelines of the Declaration of Helsinki, and approved by the Built Environment Human Research Advisory Panel of UNSW Sydney (HC200035, 3 February 2020).

Informed Consent Statement: Informed consent was obtained from all subjects involved in the study.

Data Availability Statement: The data from the case study investigation that underpins the decisionmaking framework for regenerative precinct development are not publicly available as the participants of this research study did not consent for their data to be shared publicly.

Acknowledgments: We would like to acknowledge and thank all the participants of the research study that this framework is developed upon, who generously gave up their time during the peak of a global pandemic. The authors would also like to thank the anonymous reviewers for their valuable feedback that has led to significant improvements to the quality and clarity of this paper.

Conflicts of Interest: The authors declare no conflict of interest.

\section{Appendix A}

Core THeme C: EXPANDing SHAREd REsPonsibILITY FOR the VIsion

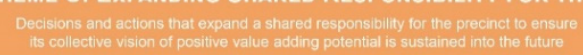

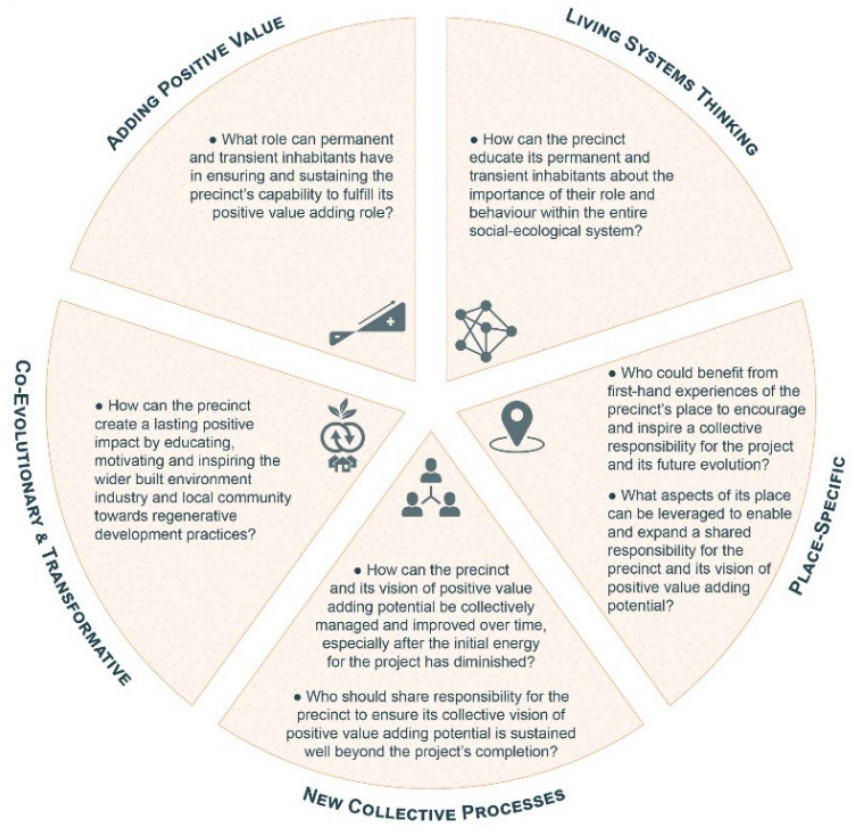

Core Theme D: Positive Transformations Enabled by the Vision The postive transtomatitons that are enabled from the procossses of bullding, Implementing and
sharing responsibility for the precinct's collective vision of positive value adding potential

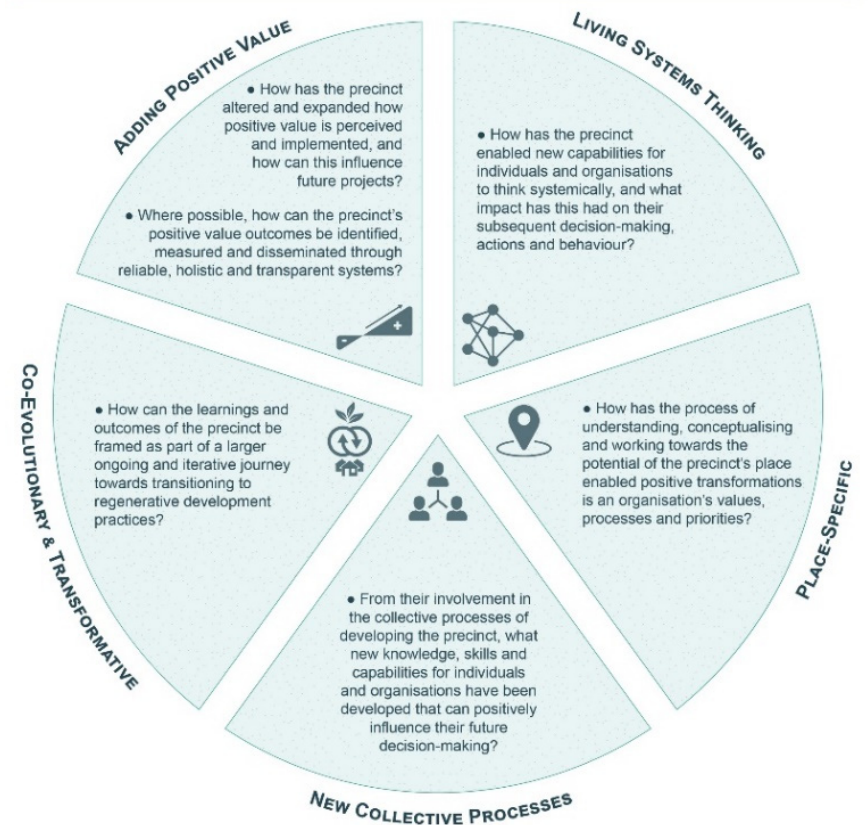

Figure A1. Decision-Making Guidance for Core Themes C and D.

\section{References}

1. IPCC. Summary for Policymakers. In Global Warming of $1.5^{\circ} \mathrm{C}$. An IPCC Special Report on the Impacts of Global Warming of $1.5^{\circ} \mathrm{C}$ above Pre-Industrial Levels and Related Global Greenhouse Gas Emission Pathways, in the Context of Strengthening the Global Response to the Threat of Climate Change, Sustainable Development, and Efforts to Eradicate Poverty; Masson-Delmotte, V., Zhai, P., Pörtner, H.-O., Roberts, D., Skea, J., Shukla, P.R., Pirani, A., Moufouma-Okia, W., Péan, C., Pidcock, R., et al., Eds.; Cambridge University Press: Cambridge, UK, 2021.

2. Reed, B. Shifting from 'sustainability' to regeneration. Build. Res. Inf. 2007, 35, 674-680. [CrossRef]

3. Cole, R.J. Regenerative design and development: Current theory and practice. Build. Res. Inf. 2012, 40, 1-6. [CrossRef] 
4. Du Plessis, C.; Brandon, P. An ecological worldview as basis for a regenerative sustainability paradigm for the built environment. J. Clean. Prod. 2015, 109, 53-61. [CrossRef]

5. Grierson, D. The shift from a mechanistic to an ecological paradigm. Int. J. Environ. Cult. Econ. Soc. Sustain. 2009, 5, 197-206. [CrossRef]

6. Hes, D.; Du Plessis, C. Designing for Hope: Pathways to Regenerative Sustainability; Routledge: Abingdon, UK, 2015.

7. Mang, P.; Reed, B. Designing from place: A regenerative framework and methodology. Build. Res. Inf. 2012, 40, 23-38. [CrossRef]

8. Gareau, B.J. Worlds Apart: A Social Theoretical Exploration of Local Networks, Natural Actors, and Practitioners of Rural Development in Southern Honduras. Sustainability 2012, 4, 1596-1618. [CrossRef]

9. White, D.; Rudy, A.; Gareau, B. Environments, Natures and Social Theory: Towards a Critical Hybridity; Palgrave: London, UK, 2015.

10. White, D.F.; Gareau, B.J.; Rudy, A.P. Ecosocialisms, Past, Present and Future: From the Metabolic Rift to a Reconstructive, Dynamic and Hybrid Ecosocialism. Capital. Nat. Soc. 2017, 28, 22-40. [CrossRef]

11. Gareau, B.J. Class Consciousness or Natural Consciousness? Socionatural Relations and the Potential for Social Change: Suggestions from Development in Southern Honduras. Rethink. Marx. 2008, 20, 120-141. [CrossRef]

12. Mang, P.; Haggard, B. Regenerative Development and Design: A Framework for Evolving Sustainability; Wiley: Hoboken, NJ, USA, 2016.

13. Plaut, J.; Dunbar, B.; Gotthelf, H.; Hes, D. Regenerative Development through LENSES with a case study of Seacombe West. Environ. Des. Guide 2016, 11, 1-19.

14. Gibbons, L.V. Regenerative-The New Sustainable? Sustainability 2020, 12, 5483. [CrossRef]

15. Camrass, K. Urban regenerative thinking and practice: A systematic literature review. Build. Res. Inf. 2021, 1-12. [CrossRef]

16. Haselsteiner, E.; Rizvanolli, B.V.; Villoria Sáez, P.; Kontovourkis, O. Drivers and Barriers Leading to a Successful Paradigm Shift toward Regenerative Neighborhoods. Sustainability 2021, 13, 5179. [CrossRef]

17. Liaros, S. Implementing a new human settlement theory: Strategic planning for a network of regenerative villages. Smart Sustain. Built Environ. 2019, 9, 258-271. [CrossRef]

18. Waldron, D.; Cayuela, A.; Miller, D. Regenerative neighbourhoods-Scaling up from net positive buildings. In Proceedings of the CaGBC National Conference \& Expo, Vancouver, BC, USA, 4-6 June 2013; pp. 80-93.

19. Centre for Living Environments and Regeneration. LENSES Overview Guide-How to Create Living Environments in Natural, Social, and Economic Systems; Centre for Living Environments and Regeneration: Fort Collins, CO, USA, 2018.

20. Birkeland, J. Net-Positive Design and Sustainable Urban Development; Routledge: New York, NY, USA, 2020.

21. Craft, W.; Ding, L.; Prasad, D. Understanding Decision-Making in Regenerative Precinct Developments. J. Clean. Prod. 2021. submitted for publication.

22. Robinson, J.; Cole, R.J. Theoretical underpinnings of regenerative sustainability. Build. Res. Inf. 2015, 43, 133-143. [CrossRef]

23. Mang, N. Toward a Regenerative Psychology of Urban Planning. Ph.D. Thesis, Saybrook University, Pasadena, CA, USA, 2009.

24. Cole, R.J.; Busby, P.; Guenther, R.; Briney, L.; Blaviesciunaite, A.; Alencar, T. A regenerative design framework: Setting new aspirations and initiating new discussions. Build. Res. Inf. 2012, 40, 95-111. [CrossRef]

25. Mang, P.; Reed, B. The nature of positive. Build. Res. Inf. 2015, 43, 7-10. [CrossRef]

26. Dos Santos, P.H.; Neves, S.M.; Sant'Anna, D.O.; Oliveira, C.H.d.; Carvalho, H.D. The analytic hierarchy process supporting decision making for sustainable development: An overview of applications. J. Clean. Prod. 2019, 212, 119-138. [CrossRef]

27. Bonabeau, E. Decisions 2.0: The power of collective intelligence. MIT Sloan Manag. Rev. 2009, $50,45$.

28. Yin, R.K. Case Study Research and Applications: Design and Methods, 6th ed.; SAGE Publications: Los Angeles, CA, USA, 2018.

29. Braun, V.; Clarke, V. Using thematic analysis in psychology. Qual. Res. Psychol. 2006, 3, 77-101. [CrossRef]

30. Braun, V.; Clarke, V. Thematic analysis. In APA Handbook of Research Methods in Psychology, Vol 2: Research Designs: Quantitative, Qualitative, Neuropsychological, and Biological; APA handbooks in psychology®; American Psychological Association: Washington, DC, USA, 2012; pp. 57-71.

31. Yin, R.K. Qualitative Research from Start to Finish, 2nd ed.; The Guilford Press: New York, NY, USA, 2016.

32. Hes, D.; Stephan, A.; Moosavi, S. Evaluating the Practice and Outcomes of Applying Regenerative Development to a Large-Scale Project in Victoria, Australia. Sustainability 2018, 10, 460. [CrossRef]

33. Byrne, J.; Mouritz, M.; Taylor, M.; Breadsell, J.K. East Village at Knutsford: A Case Study in Sustainable Urbanism. Sustainability 2020, 12, 6296. [CrossRef]

34. Plaut, J.M.; Dunbar, B.; Wackerman, A.; Hodgin, S. Regenerative design: The LENSES Framework for buildings and communities Build. Res. Inf. 2012, 40, 112-122. [CrossRef]

35. Gibbons, L.V.; Pearthree, G.; Cloutier, S.A.; Ehlenz, M.M. The development, application, and refinement of a Regenerative Development Evaluation Tool and indicators. Ecol. Indic. 2020, 108, 105698. [CrossRef]

36. International Living Future Institute. Living Building Challenge 4.0: A Visionary Path to a Regenerative Future; International Living Future Institute: Seattle, WA, USA, 2019.

37. International Living Future Institute. Living Community Challenge 1.2: A Visionary Path to a Regenerative Future; International Living Future Institute: Seattle, WA, USA, 2017.

38. Bioregional. Implementing One Planet Living: A Manual; Bioregional: London, UK, 2018.

39. Svec, P.; Berkebile, R.; Todd, J.A. REGEN: Toward a tool for regenerative thinking. Build. Res. Inf. 2012, 40, 81-94. [CrossRef] 
40. Pedersen Zari, M.; Hecht, K. Biomimicry for Regenerative Built Environments: Mapping Design Strategies for Producing Ecosystem Services. Biomimetics 2020, 5, 18. [CrossRef] [PubMed]

41. DevelopmentWA. Innovation through Demonstration. Available online: https://developmentwa.com.au/our-work/innovationthrough-demonstration (accessed on 18 January 2021).

42. Rau, T.J.; Koch-Gonzalez, J. Many Voices One Song: Shared Power with Sociocracy; Sociocracy For All: Amherst, MA, USA, 2018. 